\title{
Heterosporis finki, a microsporidian parasite of the angel fish Pterophyllum scalare: pathology and ultrastructure
}

\author{
C. Michel ${ }^{1}$, J. Maurand ${ }^{2}$, C. Loubès ${ }^{2}$, S. Chilmonczyk ${ }^{1}$, P. de Kinkelin ${ }^{1}$ \\ ${ }^{1}$ Institut National de Recherche Agronomique, Station de Virologie et d'Immunologie moléculaires, Laboratoire \\ d'Ichtyopathologie, Centre de Recherches de Jouy, F-78 350 Jouy en Josas, France \\ ${ }^{2}$ Université des Sciences et techniques du Languedoc, Lab. d'Ichthyologie et de Parasitologie générale, Place Eugène Bataillon, \\ F-34 060 Montpellier, France
}

\begin{abstract}
A severe case of microsporidian infection was observed in farmed Pterophyllum scalare Curs \& Valens, 1831, in 1987 and resulted in the complete destruction of the stock. Juveniles were severely affected by the parasite; a milky degeneration of skeletal muscle was produced, in which developmental stages of the parasite could be observed. Adult fish appeared more resistant to infection and were only lightly infected. Light and electron microscope observations on developmental stages and spores of the causative agent were sufficient to identify the parasite as Heterosporis finki Schubert, 1969. This parasite had already been reported in $P$. scalare, but this is the first time that its pathogenicity and its clinical significance for intensive farming systems are clearly assessed.
\end{abstract}

\section{INTRODUCTION}

Microsporidian parasites are common in ornamental fish (Reichenbach-Klinke \& Elkan 1965). Although many species associate with different fish-host tissues without the appearance of harmful effects, others can produce serious infections resulting in high mortalities The most documented of these diseases is the neon tetra disease caused by Pleistophora hyphessobryconis Schäperclaus, 1941 (Schäperclaus 1941, van Duijn 1967), but other clinical cases due to Glugea spp. have been recorded in a variety of fish species (Pflugfelder 1952, Cotton, quoted by van Duijn 1967). It is noteworthy that many of these pathogens primarily affect the myoblasts.

In early 1987 a chronic condition, associated with significant losses, occurred in young Brazilian angel fish Pterophyllus scalare Curs \& Valens, 1831, hatched on a farm located in the south-east of France and devoted to ornamental fish production. On several occasions between May and December, fish samples were collected and shipped alive to our laboratories. In all cases microsporidian spores were observed in large numbers in the muscles. The relevant investigations and conclusions are reported in this paper.

\section{MATERIALS AND METHODS}

Clinical observations were first performed at the farm. Contrary to adult fish (which were kept as pairs in aquaria individually fitted with filter systems and which never exhibited any clinical sign) juveniles were stocked in 150 or $300 \mathrm{l}$ glass-tanks supplied with water from a recirculating unit. Water was heated to $26^{\circ} \mathrm{C}$ and treated by UV irradiation at the filter outlet. This precaution did not prevent the disease from spreading quickly to the whole system, although other fish species reared in the same system remained uninfected.

The sampled fish were generally young individuals 2 to $4 \mathrm{~cm}$ long and exhibiting clinical signs, although in some cases, apparently healthy adults were obtained. Fish were sacrificed in 2-phenoxy-ethanol 1/500 (Eastman Kodak) and examined according to routine techniques involving microscopic observation of fresh mounts, or tissues smears and imprints stained with toluidine blue, May-Grünwald-Giemsa, Delamater or Prenant. Occasionally, bacteriological samples were taken by spreading affected tissues onto trypticasesoya-agar (TSA). Isolated bacteria were identified using API 20 E units (API System, La Balme les Grottes, France). 

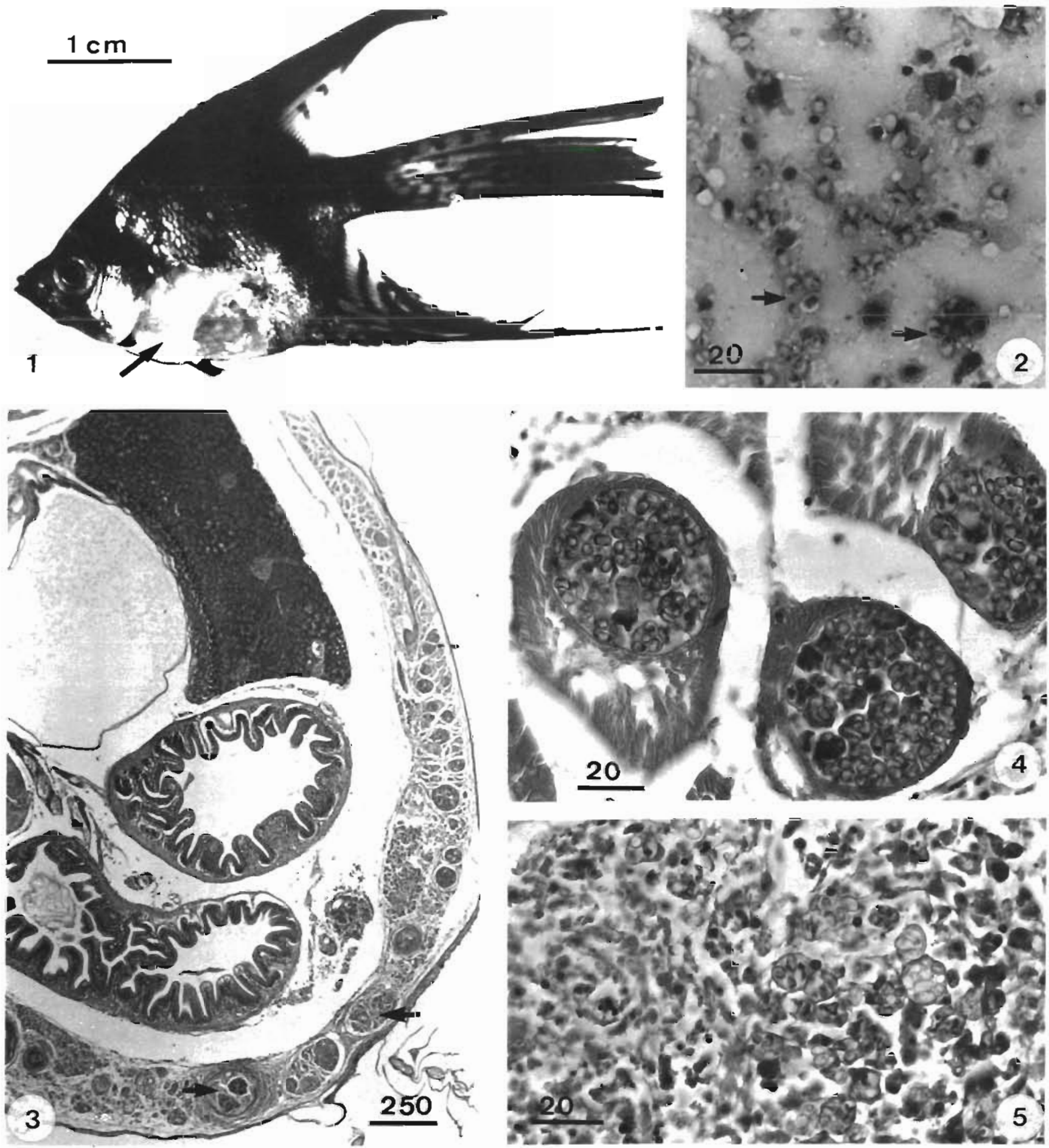

Figs. 1 to 5. Hetcrosporis finki. Fig. 1. Macroscopic appearance of the infection in Pterophyllum scalare; after partial. dissection and removal of tho skin, the muscular degeneration of the body wall appears as a whitish milky mass (arrow). Fig. 2. Microsporidian spores in a toluidine blue stained smear of infected muscle (arrows). Fig. 3. Paraffin cross section of an infected fish: the muscles of the body wall are filled with xenomas of various sizes (arrows), and the parasitic material constitutes more than $2 / \mathrm{s}$ of the body wall surface (H\& E). Fig. 4. Paraffin cross section of infected myocytes showing xenomas filled with spores (H \& E). Fig. 5 . Paraffin section of a degenerated parasitised muscular area showing both isolated and grouped spores scattered among the tissues debris $(H \& E)$. Except in Fig. 1, all scale bars are labelled in um 
Small fish (less than $3 \mathrm{~cm}$ ), samples of fish tissue and organs, or xenomas carefully dissected from muscle, were processed for histopathology. Samples were placed into Bouin's or Carnoy's fixatives, decalcified when required in RDO (Eurobio, France), then dehydrated with ethanol, embedded in paraffin wax, sectioned at $5 \mu \mathrm{m}$ and stained with hematoxylin and eosin (H \& E) or Masson's trichrome.

For ultrastructural studies, $2 \mathrm{~mm}^{3}$ samples of infected tegument and/or muscle were fixed for $2 \mathrm{~h}$ at $4{ }^{\circ} \mathrm{C}$ in $1.25 \%$ glutaraldehyde buffered with sodium cacodylate (0.1 M, pH 7.3), then post-fixed overnight in $2 \%$ osmium tetroxide in the same buffer. After dehydration in ethanol and propylene oxide, samples were embedded in Epon. Ultrathin sections $(50 \mathrm{~nm}$ ) were cut using a LKB ultramicrotome, stained with uranyl acetate and lead citrate according to the method of Reynolds (1963), and observed on a Philips 300 electron microscope operated at $80 \mathrm{kV}$. Other samples, including isolated xenomas, were directly fixed in $2 \%$ osmium tetroxide (in Palade's buffer, pH 7.4) and further processed as indicated above. Semithin sections for light microscopy were cut at $1 \mu \mathrm{m}$ and stained with methyl blue and Azur II.

\section{RESULTS}

\section{Clinical observation}

Few fish exhibited clinical signs, but most young individuals appeared in poor condition and displayed some degree of emaciation. Skin lesions, starting as discoloured or greyish spots, were noticed on the flank of some. In the most severe cases these extended and produced necrotic areas of ca $5 \mathrm{~mm}$ diam. and were filled with soft white friable tissue. Ragged fins and small haemorrhages at the pectoral fin girdle were sometimes observed, but were presumably caused by secondary bacterial invasion in seriously debilitated fish. In fact, the most typical lesion was found when dissecting fish: the whole musculature had altered to a milky white tissue of creamy texture (Fig. 1), which strongly contrasted with the seemingly normal appearance of internal organs

Fresh preparations and smears of muscle tissue stained with toluidine blue revealed the typical picture of a microsporidial infection, with large numbers of egg-shaped elements, $8 \times 3$ to $5 \mu \mathrm{m}$, loosely scattered through the field or associated in small clusters (Fig. 2). These spores were found in all fish tested, even when clinical signs were lacking. They could also be recognized in adult fish, but in significantly less numbers. Histological sections obtained from heavily infected fish confirmed that, although the viscera had retained their normal structure, striated muscles were extensively destroyed and filled with cystic formations of different sizes and stages of maturation (Fig. 3). These xenomas, or parasitophorous vacuoles, developed inside degenerated muscular fibers which could rupture, dispersing their contents (Figs. 4 to 6).

Bacteria belonging mainly to Aeromonas hydrophila and Citrobacter groups were isolated, but none were consistantly found associated with the disease, and their appearance as secondary invaders seems likely.
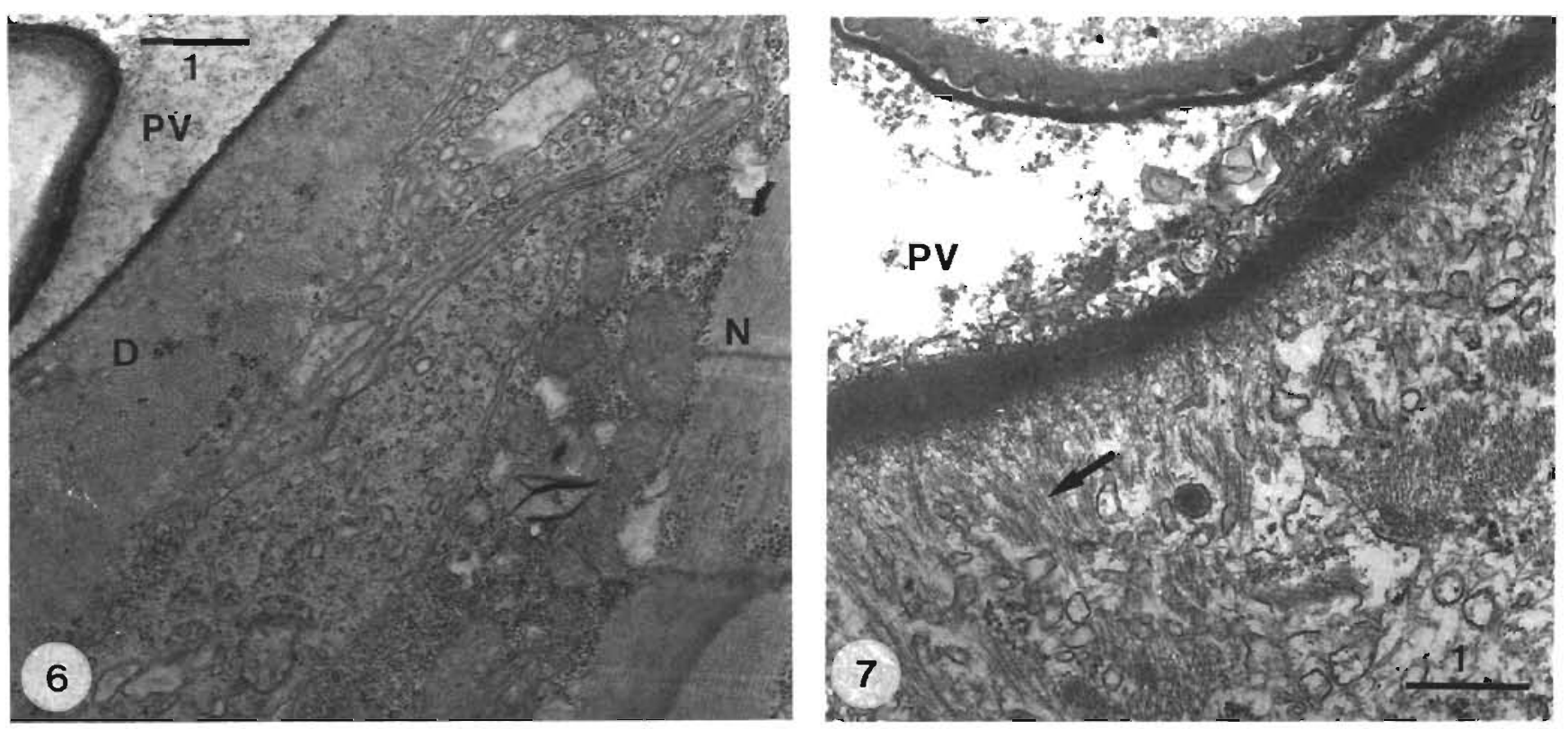

Figs. 6 and 7. Heterosporis finki. Fig. 6. Ultrathin section of the contact between a normal myocyte (N) and a degenerated myocyte (D) containing a xenoma, or parasitophorous vacuole (PV). Fig. 7 . Ultrathin section showing the structural connections (arrow) which seem to exist between wall of the xenoma and infected myocyst. Scale bars in $\mu \mathrm{m}$ 


\section{Study of the parasite}

Light and electron microscopy permitted recognition of subspherical cysts (within muscular fibers) as xenomas, $60 \mu \mathrm{m}$ diam. These formations contained different developmental stages of the parasite, and both merogonic and sporogonic stages, including maturing sporophorous vesicles (or sporophorous vacuoles). A noteworthy feature was the thickness of xenoma walls (Fig. 7). Although they could be easily
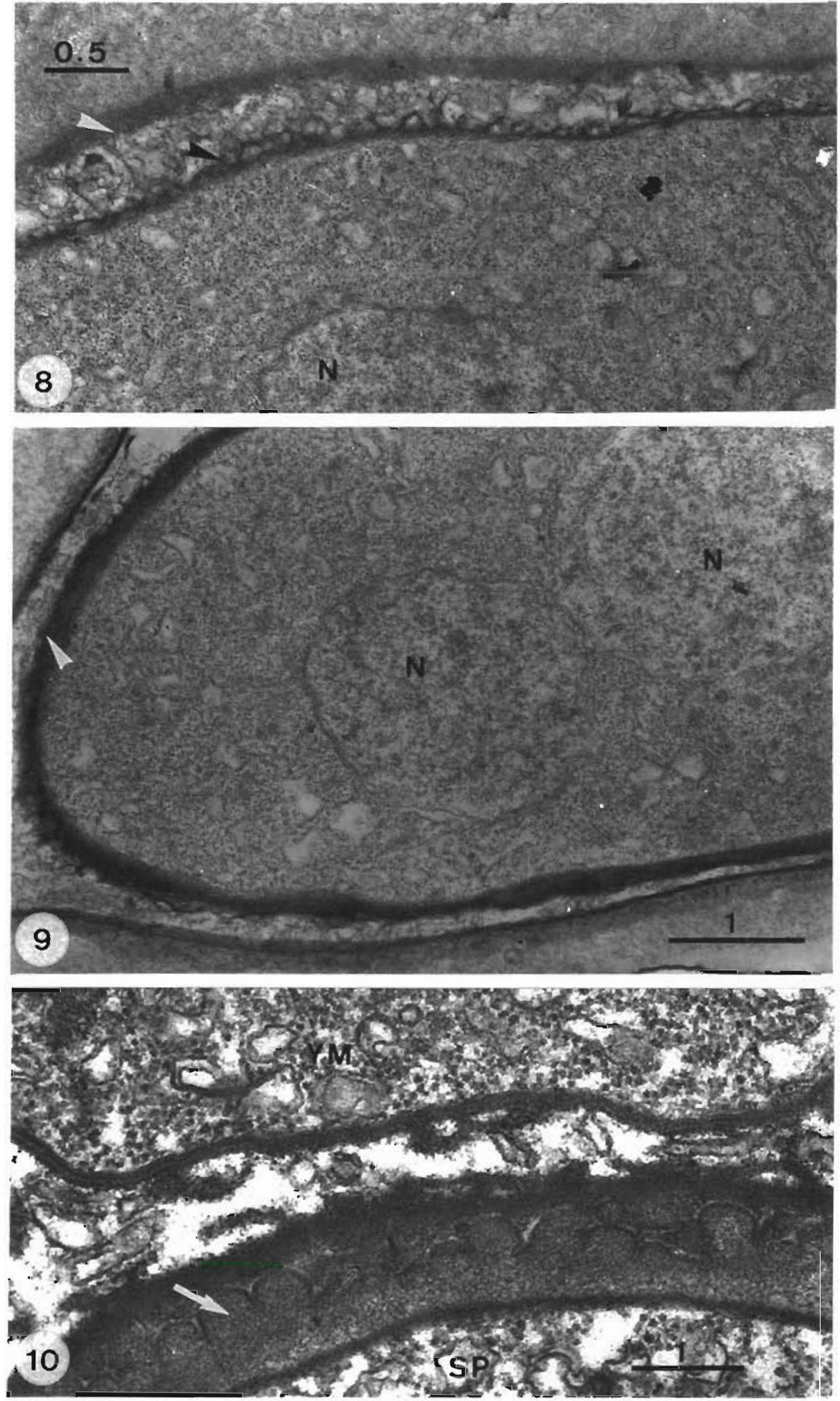

Figs. 8 to 10 . Heterosporis finki. Membrane reorganization during the transformation of the meront into a sporont. Fig. 8. Delamination (black arrow) of the outer membrane of the meront. White arrow: wall of the xenoma; $\mathrm{N}$ : nucleus of the meront. Fig. 9. Formation of the wall of the future sporophorous vesicle (white arrow). $N$ : nuclei of the meront. Fig. 10. Cytoplasmic material (arrow) accumulates between the outer membrane and the cytoplasmic membrane of the sporont, resulting in a thick wall. SP: sporogonial plasmodia; YM: young meront Scale bars in $u m$ 
removed and isolated, relationships seem to exist with the surrounding disorganized myofibrillae (Fig. 7), and suggest that some components of the host tissues could participate in wall formation. The degeneration of myofibrils could also mean that soluble components are released around the xenomas.

\section{Merogony}

Typical meronts showing a diplocaryon and 2 cell membranes could not be observed adequately, but undoubtedly exist as diplocaryons could be visualized in more advanced stages (Fig. 9). It is assumed that plasmodial merogonic forms may appear during the preceding cell multiplication. During conversion of the meront into a sporont, the 2 nuclei split, and a characteristic reorganization of the membranes occurred. The active transformation of the outer membrane led to the formation of the thick sporophorous vesicle wall. At the same time, a cytoplasmic substance was discharged through the inner membrane and accumulated in the space between the 2 membranes, producing small spheres which merged readily and lined the sporophorous vesicle wall (Figs. 8 to 10).

\section{Sporogony}

Two nuclear divisions occurred in young sporonts, resulting in sporogonial plasmodia which contained 8 nuclei. Then, the plasmodia completed their division, producing uninucleate sporoblasts (Fig. 11) each resulting in a spore (Fig. 12). Spores were generally grouped in 8 (Figs. 13 to 15), were ovoid in shape, 8 to $9 \times 3$ to $5 \mu \mathrm{m}$, and possessed a very long polar filament (130 to $150 \mu \mathrm{m}$ ) which formed 30 to 33 whorls when coiled in the spore (Fig. 12). Surprisingly, the nuclear material was not stained by Delamater's method, which generally reacts positively with other Microsporidia.

\section{DISCUSSION}

The parasite observed in diseased Pterophyllum scalare was easily ascribed to the class Microsporidia, and the regular observation of sporogonous vesicles containing groups of 8 spores seemed to relate this form to the genus Thelohania. However, Schubert (1969a, b) had described a similar organism in P. scalare, which he named Heterosporis finki derived from the observation that spores of small size, called microspores, were occasionally observed. Although Schubert did not give any indication of the possible pathogenicity of $H$. finki, which appeared as a casual discovery and was only associated with the oesophageal walls of some fish, the microsporidian species described in the present work appeared similar to $H$. finki. The structure and size of spores, the characteristics of the polar filament, the organization of the sporophorous vesicle wall, and the host species involved were found to comply with the descriptions of Schubert (1969a, b) - although the rare microspores described by this author (1969a) were not observed. The muscular site and intensity of infection were previously unreported and demonstrate the pathogenic potential of this parasite.

It was not possible to fulfil Koch's postulates. Healthy Pterophyllum scalare were unavailable because fish remaining on the farm were considered potential carriers, and during outbreaks of the disease there was a dramatic reduction in the trade of this species - seemingly due to different pathological problems. Nevertheless, the microsporidian aetiology of the condition was confirmed by the consistent presence of microsporidian spores and developmental stages associated, and by the fact that no other pathogen was consistantly identified from diseased $P$. scalare. It was noticeable that other fish species present in the same rearing unit remained healthy and that spores were found in all clinically normal angel fish checked. Therefore $H$. finki appears to be a specific and significant threat for $P$. scalare reared in a confined environment.

The origin of infection remains conjectural. Although fish were reared under controlled conditions, fresh food consisting of zooplankton of wild origin had been fed at several times during the year prior the occurrence of the disease. However, it was not possible to demonstrate the presence of any type of Microsporidia in plankton and the comparison of our data with those of Schubert (1969a, b) suggests the exotic origin of a parasite species specifically hosted by Pterophyllum scalare - in such a case adult fish could have been introduced as carriers. Their apparent resistance and low level of infection could be explained by their age and by optimal conditions of maintenance (2 fish $\tan k^{-1}$ ). However, such conditions could not avoid the spores being shed at low level, leading to infection of progeny. Attempts to detect spores in ovaries, as for neon tetra disease caused by Pleistophora hyphessobryconis, were unfortunately negative. Once infection had been introduced into the recirculating unit, the parasite could logically thrive and amplify its effects.

This report provides an additional observation to the already flourishing list of Microsporidia in ornamental fish. Now, Heterosporis finki appears as a potential pathogen. As expected from previous work by Loubès $(1979 b)$, different development stages of the parasite were observed in parasitophorous vacuoles and were allowed to complete their life-cycle. Merogony was characterized by diplocaryons which split at the be- 

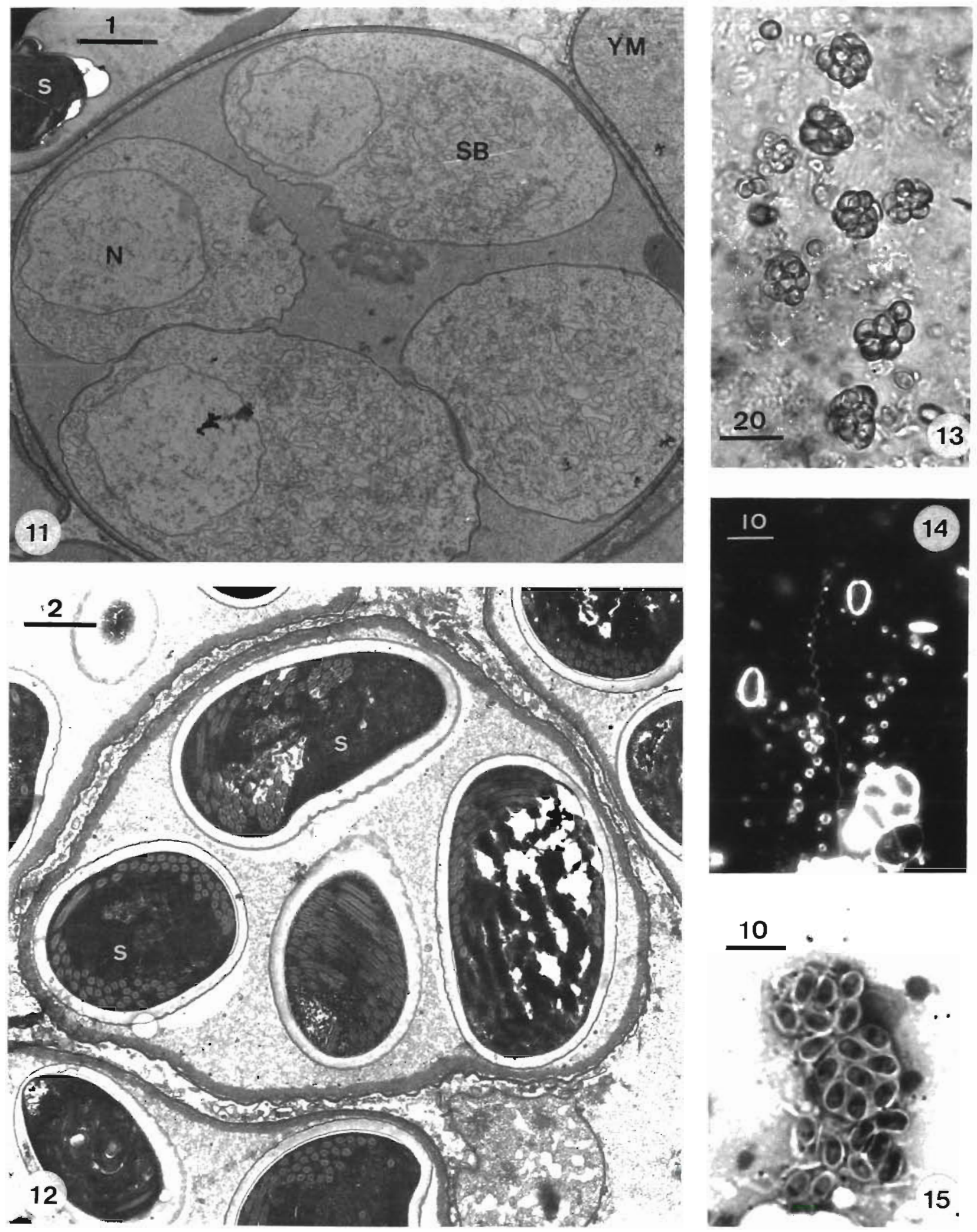

Fig. 11 to 1.5. Heterosporis finki. Fig. 11. Ultrathin section of uninucleate sporoblasts in the sporophorous vesicle. SB: sporoblast; N: nucleus; YM: young meront: S: spore. Fig. 12. Sporophorous vesicle with completely developed spores (S). Fig. 13. Fresh mount of spores observed in direct light microscopy. Fig. 14. Fresh mount of spores observed in dark field microscopy, showing an evaginated polar filament. Fig. 15. Prenant's stained smear of sporophorous vesicles and spores. Scale bars in um 
ginning of sporogony, as observed in other species (Loubès 1979a). Meiotic chromosomes were not observed, but it is likely that each diploid nucleus can produce 4 haploid nuclei, resulting in an octosporous pansporoblast as described by Loubès (1979a) in other genera. In contrast to Schubert (1969b), nuclei did not disappear during sporogony and were difficult to visualize in mature spores.

According to Canning \& Lom (1986) the parasite could be closely related to the genus Pleistophora. However, on the basis of the haploid mononucleate octospores, Sprague (1977) included it in the genus Heterosporis Schubert, 1969, family Thelohaniidae (which mainly comprises parasites of invertebrates). Compared to related genera, Heterosporis is characterized by the thickness of its sporophorous vesicle wall. It must be noted that thick walls have been described in other $\mathrm{Mi}$ crosporidia, namely the insect parasite Vavraia Weiser, 1977 (Canning \& Hazard 1982, Malone et al. 1987), and the fish parasite Pleistophora Gurley, 1893 (Lom \& Corliss 1967, Canning \& Nicholas 1980). The possible taxonomic value of this wall has still to be assessed.

Another striking feature that Heterosporis seems to share with some representatives of the genera Pleistophora and Thelohania is its tropism for muscular cells, and indeed, the muscular lesions observed in Pterophyllum scalare resembled what is classically seen in porcelain disease of crayfish. It is assumed that, under natural conditions, fish can tolerate a mild parasitism. The enhanced infectivity of Microsporidia in restricted or overcrowded conditions make them a significant threat to intensive fish farming

The clinical severity and usually fatal prognosis of such infections are heightened by the current lack of effective therapy. We did not have the opportunity to check the efficacy of Fumagillin, an antibiotic which has been proved effective against nosemosis of bees and tried in eel microsporidiosis (Kano et al. 1982). This was because fish stocked on the farm were destroyed after the diagnosis was made, and the whole rearing facility redesigned to prevent the spread of further similar infections. In future, the construction of special rearing facilities for ornamental fish will have to take in to account the prevention of microsporidian infections, namely by paying attention to the organization of strict quarantine systems.

Responsible Subject Editor: Professor W. Körting, Hannover, F.R. Germany

\section{LITERATURE CITED}

Canning, E. U., Hazard, E. J. (1982), Genus Pleistophora Gurley, 1893: an assemblage of at least three genera. J Protozool. 29: 39-49

Canning, E. U., Lom, J. (1986). The Microsporidia of Vertebrates. Academic Press, New York, p. 136-138

Canning, E. U., Nicholas, J. P. (1980). Genus Pleistophora (Phylum Microspora): redescription of the type-species Pleistophora typicalis Gurley, 1893 and ultrastructural characterization of the genus. J. Fish Dis. 3: 317-338

Duijn, C. van (1967). Diseases of fishes. Illife Books, London

Kano, T., Okauchi, T., Fukui, H. (1982). Studies on Pleistophora infection in eel, Anguilla japonica. II Preliminary tests for application of Fumagillin. Fish Pathol. 17: 107-114

Lom, J., Corliss, J. O. (1967). Ultrastructural observations on the development of the microsporidian protozoon Pleistophora hyphessobryconis Schäperclaus. J. Protozool. 14 $141-152$

Loubès, C. (1979a). Recherches sur la méïose chez les Microsporidies: conséquences sur les cycles biologiques. J. Protozool. 26: 200-208

Loubès, C. (1979b) Ultrastructure, sexualité, dimorphisme sporogonique des Microsporidies (Protozoaires) Incidences taxonomiques et biologiques. Th. Doct. ès Sc. U.S.T.L., Montpellier

Malone, L. A., Wigley, P. J., Dhana, S. D. (1987). Identity of a microsporidium from three New Zealand pasture insects: Costelytra zealandica (Coleoptera, Scarabeidae), Wisena spp. (Lepidoptera, Hepialidae) and Listronotus bonariensis (Coleoptera, Curculionidae). J. Invertebr Path. 49: 135-144

Pflügfelder, O. (1952). Die sogenannten Restkörper der Cyprinodontidae und Cyprinidaea als Abwehrreaktionen gegen Mikrosporidienbefall. Z. Parasitenk. 15: 321-334

Reichenbach-Klinke, H., Elkan, E. (1965). The principal diseases of lower vertebrates. Diseases of fishes. T.F.H. Publ. Neptune City, New Jersey

Reynolds, E. S. (1963). The use of lead citrate at high pH. as an electron-opaque stain in electron microscopy. J. biophys. biochem. Cytol. 17: 208-212

Schäperclaus, W. (1941). Eine neue Mikrosporidienkrankheit beim Neonfisch und seinen Verwandten. Wochenschr. Aqua. Terr. 38: 381-384

Schubert, G. (1969a). Ultracytologische Untersuchungen an der Spore der Mikrosporidienart, Heterosporis finki, gen. n., sp. n. Z. Parasitenk. 32: 59-79

Schubert, G. (1969b). Elektronenmikroskopische Untersuchungen zur Sporonten und Sporenentwicklung der Mikrosporidienart Heterosporis finki. Z. Parasitenk. 32 $80-92$

Sprague, V (1977). Systematics of the Microsporidia. In: Bulla, L. A. Jr, Cheng, T C. (ed.) Comparative Pathobiology, Vol. 2

Manuscript first received: April 29, 1989

Revised version accepted: August 4, 1989 